International Journal of Integrative Pediatrics and Environmental Medicine, V5, 2020, 34-37

Editorial The COVID 19 pandemic has materially changed my pediatric nephrology practice and medical school clinical supervision. Baghchechi and Jacob offered valuable and timely suggestions for scheduling care when supervising resident training.

T.L. Vasylyeva MD PhD, Managing Editor.

\title{
THE NEW FACE OF MEDICINE - CARE FLOW STRATEGIES DEVELOPED DURING COVID
}

\author{
Mohsen Baghchechi ${ }^{1}$ and Sharon E. Jacob ${ }^{1,2,3^{*}}$
}

Author information: ${ }^{1}$ University of California, Riverside, School of Medicine, ${ }^{2}$ Loma Linda University, Department of Dermatology, ${ }^{3}$ Veterans Health Administration, Loma Linda, CA

\begin{abstract}
The COVID-19 pandemic has redefined the practice of medicine. Adaptive care models to sustain access through integration of virtual and in person essential services have been implemented. Utilization of novel scheduling protocols can create a safe and efficient clinic experience for children and staff in this pandemic time.
\end{abstract}

Keywords: COVID-19, public health, telemedicine, dermatology, prevention

BACKGROUND The coronavirus pandemic has offered a major opportunity to restructure access maintenance to medical care in the United States. There has been a dramatic drop-off in face-to-face patient care visits to medical practices since March $15^{\text {th }}$, as the coronavirus spread worldwide. As of June 10 , the worldwide case total has eclipsed over 7 million with $>400,000$ deaths [1]. The US continues to lead the world with 1.9 million total cases and $>110,000$ deaths (Figure 1) [2].

\section{Pediatric manifestations}

Early on, children were believed to be at lower risk for COVID-19 related consequences [3]. More recent reports have identified clusters of cases of a Kawasaki-like disease associated with COVID-19, currently being named pediatric multisystem inflammatory syndrome (PMIS) [46]. These children presented with high fevers, desquamating rashes, and coronary aneurysmal disease [4]. Serology testing in multiple patients were positive for prior COVID-19 infection, suggesting a possible hyper stimulated inflammatory reaction in children exposed to the virus. Another presentation seen in children are pernio-like acral lesions, which are being referred to as 'COVID-Toes' [7-9]. Other presentations range from nonspecific erythematous rashes, vesicular chickenpox like

\footnotetext{
*Corresponding author: Sharon E. Jacob Department of Dermatology, 11370 Anderson Street, Suite 2600, Loma Linda, CA 92354, E-mail address: sjacob@contactderm.net Mohsen Baghchechi, Sharon E. Jacob (C)
}

rash, and livedo reticularis [10-12]. Identification of dermatologic findings in children can help with early recognition and diagnosis and avoid delayed diagnosis due to atypical findings. Early recognition of these presentations is vitally important in reducing COVID-19 transmission through appropriate triage and allowing for early intervention.

\section{Access to Care in COVID-19}

There has been a decrease in face-to-face dermatology care visits as individuals have stayed away from medical offices, fearful of contracting COVID-19. The response from the medical community has been to substantially increase access through telehealth and to utilize virtual care to rapidly assess patients for COVID-19. This has been hailed by public health authorities, the Center for Disease Control (CDC) and the American Academy of Dermatology (AAD) as a critical initiative that should be sustained [1314]. The provision of telecare in the academic training setting requires a redesign in the base model of care and teaching, in addition to a significant change in management oversight [15-16].

Herein, we outline a model for integrating face-to-face essential care and telecare visits (Table 1). Appointment slots are staggered between virtual and in-person care between the resident physicians and attending.

\section{Care flow strategy}

The resident connects virtually with the patient/caregiver and initiates the visit (attains chief complaint, pertinent 


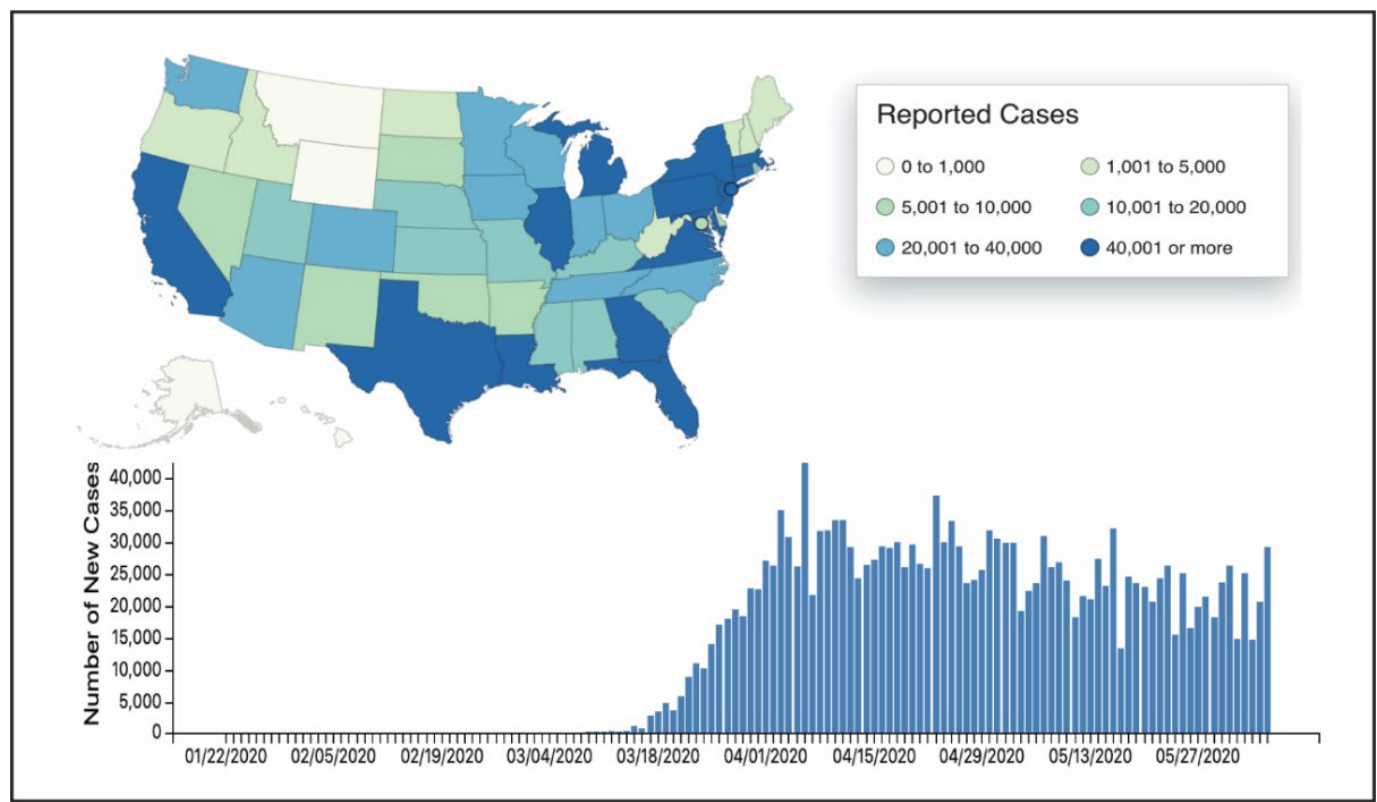

Figure 1. COVID-19 pandemic case tracker across the United States [Reproduced with permission from the World Health Organization].

\begin{tabular}{|c|c|c|c|}
\hline \multirow{2}{*}{\multicolumn{3}{|c|}{ Initiation of Care: }} & \multirow[t]{2}{*}{ Time Attending Enters: } \\
\hline \multirow{2}{*}{\multicolumn{3}{|c|}{\begin{tabular}{l|l}
\multicolumn{2}{l}{ Resident $\mathbf{w} / \mathbf{P T}$} \\
Time & Patient (Virtual)
\end{tabular}}} & \\
\hline & & & Available to chief virtual \\
\hline $8: 00$ & Hold & Res Z - Virtual Urgent seen directly w/attending & \\
\hline 8:00 & $A$ & $\operatorname{Res} X$ & $8: 10$ \\
\hline $8: 10$ & B & $\operatorname{Res} Y$ & $8: 20$ \\
\hline $8: 20$ & C & Res Z & $8: 30$ \\
\hline $8: 30$ & $\mathrm{D}$ & Res $X$ & $8: 40$ \\
\hline $8: 40$ & $\mathrm{E}$ & $\operatorname{Res} Y$ & $8: 50$ \\
\hline $8: 50$ & $\mathrm{~F}$ & Res Z & 9:00 \\
\hline 9:10 & Hold & Res X - Virtual Urgent seen directly w/attending & \\
\hline Time & Patient (F2f) & Resident $(x, y, z)$ & Available to chief F2f \\
\hline 9:00 & $\bar{G}$ & $\operatorname{Res} Y$ & 9:30 \\
\hline 9:15 & $\mathrm{H}$ & Res Z & 9:50 \\
\hline 9:30 & 1 & Res X & $10: 10$ \\
\hline $10: 00$ & J & Res Y & $10: 30$ \\
\hline $10: 15$ & K & $\operatorname{Res} Z$ & $10: 50$ \\
\hline $10: 30$ & Hold & Res $X$ - Access F2f & $11: 10$ \\
\hline $11: 50$ & Hold & Res Y - Virtual Urgent seen directly w/attending & \\
\hline \multicolumn{4}{|c|}{$\begin{array}{l}\text { Table 1. Flow Diagram integration of } 15 \text { care appointments optimizing face-to-face (F2F) and virtual care } \\
\text { appointments (shaded gray in table) with four reserved for urgent virtual appointments (hold). Time: Patient } \\
\text { appointment start time; Patient Slots A-K are scheduled appointments; Hold are reserved for urgent visits. } \\
\text { Residents (Res): } 3 \text { resident physicians available for patient care. F2F is essential care visit., Time Attending } \\
\text { Enters: When the attending physician begins care of patient. }\end{array}$} \\
\hline
\end{tabular}


past and current medical and social history, medicine reconciliation, allergies and preliminary physical examination). The patient/caregiver is then put in the virtual waiting room (hold status). The attending will mark themselves in available status vs. busy on their skype. The resident connects to the attending and discusses the case. The resident then connects with the attending back to the patient (virtual waiting room), where the care visit is completed. The attending marks themselves as busy. The attending then disconnects from the care visit and marks their status as available. The process is repeated. An aftervisit summary is generated with instructions for care and follow-up, which includes contact information for the nurse care line should further information be needed.

\section{REFERENCES}

1. World Health Organization. WHO Coronavirus Disease (COVID-19) Dashboard. https://covid19.who.int/?gclid=EAlalQobChMI_qX5tez c6QIVpRx9Ch0Gvwn-EAAYASABEgLzAPD_BwE.

Accessed on: June 10, 2020.

2. Centers for Disease Control and Prevention. Cases in the U.S. https://www.cdc.gov/coronavirus/2019ncov/cases-updates/cases-in-us.html. Accessed on: June 10, 2020.

3. Lee PI, Hu YL, Chen PY, Huang YC, Hsueh PR. Are children less susceptible to COVID-19? [published online ahead of print, 2020 Feb 25]. J Microbiol Immunol Infect. 2020; S1684-1182(20)30039-6. doi: 10.1016/j.jmii.2020.02.011.

4. Viner RM, Whittaker E. Kawasaki-like disease: emerging complication during the COVID-19 pandemic [published online ahead of print, 2020 May 13]. Lancet. 2020;10.1016/S0140-6736(20)31129-6. doi:10.1016/S0140-6736(20)31129-6.

5. Riphagen S, Gomez X, Gonzalez-Martinez C, Wilkinson $N$, Theocharis $P$. Hyperinflammatory shock in children during COVID-19 pandemic. Lancet.

2020;395(10237):1607-1608. doi:10.1016/S01406736(20)31094-1.

6. Verdoni L, Mazza A, Gervasoni A, et al. An outbreak of severe Kawasaki-like disease at the Italian epicentre of the SARS-CoV-2 epidemic: an observational cohort study [published online ahead of print, 2020, 13]. Lancet. 2020;10.1016/S0140-6736(20)31103-X. doi:10.1016/S0140-6736(20)31103-X.
7. Kolivras A, Dehavay F, Delplace D, et al. Coronavirus (COVID-19) infection-induced chilblains: A case report with histopathologic findings [published online ahead of print, 2020 Apr 18]. JAAD Case Rep.

2020;10.1016/j.jdcr.2020.04.011. doi:10.1016/j.jdcr.2020.04.011.

8. Recalcati S, Barbagallo T, Frasin LA, et al. Acral cutaneous lesions in the Time of COVID-19 [published online ahead of print, 2020 Apr 24]. J Eur Acad Dermatol Venereol. 2020;10.1111/jdv.16533. doi:10.1111/jdv.16533.

9. Landa N, Mendieta-Eckert M, Fonda-Pascual P, Aguirre T. Chilblain-like lesions on feet and hands during the COVID-19 Pandemic. Int J Dermatol. 2020;59(6):739743. Doi:10.1111/ijd.14937.

10.Tammaro A, Adebanjo GAR, Parisella FR, Pezzuto A, Rello J. Cutaneous manifestations in COVID-19: the experiences of Barcelona and Rome [published online ahead of print, 2020 Apr 24]. J Eur Acad Dermatol Venereol. 2020;10.1111/jdv.16530. doi:10.1111/jdv.16530.

11. Bouaziz JD, Duong $T$, Jachiet $M$, et al. Vascular skin symptoms in COVID-19: a rench observational study [published online ahead of print, 2020 Apr 27]. J Eur Acad Dermatol Venereol. 2020;10.1111/jdv.16544. doi:10.1111/jdv.16544.

12. Galván Casas C, Català A, Carretero Hernández G, et al. Classification of the cutaneous manifestations of COVID-19: a rapid prospective nationwide consensus study in Spain with 375 cases [published online ahead of print, 2020 Apr 29]. Br J Dermatol. 2020;10.1111/bjd.19163. doi:10.1111/bjd.19163.

13. American Academy of Dermatology. Coronavirus resource center. https://www.aad.org/member/practice/coronavirus. Accessed on: May 30, 2020.

14. Center for Disease Control and Prevention. Prepare your practice for COVID-19. https://www.cdc.gov/coronavirus/2019ncov/hcp/preparedness-resources.html. Accessed on: May 30, 2020.

15.Smith AC, Thomas E, Snoswell CL, et al. Telehealth for global emergencies: Implications for coronavirus disease 2019 (COVID-19) [published online ahead of 
print, 2020 Mar 20]. J Telemed Telecare.

2020;1357633X20916567.

doi:10.1177/1357633X20916567.

16. Latifi R, Doarn CR. Perspective on COVID-19: Finally, Telemedicine at Center Stage [published online ahead of print, 2020 May 14]. Telemed J E Health.

2020;10.1089/tmj.2020.0132.

doi:10.1089/tmj.2020.0132. 